\title{
Frustrative nonreward effects in acquisition under zero hours deprivation'
}

\author{
LAWRENCE DACHOWSKI and WILLIAM P. DUNLAP, \\ Tulane University, New Orleans, La. 70118
}

Facilitating effects of partial reinforcement were found when six female rats were given 80 trials in a runway under zero food deprivation and with sucrose reward pellets. The three Ss trained under 50\% reinforcement were initially slower than the $100 \%$ Ss, but with continued training finally reached higher speeds. This effect was greatest for speed measured in the middle of the response chain. The results were discussed in terms of the theories of Spence and Amsel.

A number of studies (e.g., Goodrich, 1959; Haggard, 1959; Nelson \& Wollen, 1965) have found that rats rewarded on $50 \%$ of the training trials in a straight alley show performance initially inferior to $100 \%$ rewarded animals, but with further training the $50 \%$ groups reach higher asymptotes than the $100 \%$ groups. Typically, this pattern or "crossover effect" (CE) is most pronounced in the earlier portions of the response chain; measures taken near the goal usually show consistent superiority of the $100 \%$ group (e.g., Goodrich, 1959). Spence (1960, Chap. 6) interprets the CE in terms of a frustration approach presented by Amsel (1958). Specifically, the asymptotic superiority of the $50 \%$ groups is attributed to an increase in generalized drive (D) by the addition of anticipatory frustration $\left(\mathrm{r}_{\mathrm{f}}\right)$ to the motivational complex.

McHose \& Ludvigson (1964) found that the primary frustration produced by partial reinforcement is reduced under low drive as indicated by a smaller frustration effect for Ss maintained at $90 \%$ of ad lib body weight than for Ss at $80 \%$ of ad lib body weight. If decreased primary frustration at lower drive levels leads to decreased $r_{f}$, then it might be expected that the $C E$ would be reduced, or even absent, under very low drive conditions. On the other hand, if the development of $r_{f}$ is relatively independent of drive, then the CE would occur as readily under low drive as under high drive.

Badia (1965) presented data obtained under three levels of deprivation which conform to the pattern of the $C E$. The interactions of deprivation and reward percentage were all nonsignificant, indicating that the apparent CEs did not differ as a function of drive. However, since none of the apparent CEs was significant (no significant differences in asymptotes between $50 \%$ and $100 \%$ groups), the question of the possibility of the occurrence of the $\mathrm{CE}$ at low drive remains open. The present study involved training under zero deprivation with Ss reinforced $100 \%$ or $50 \%$ with highly palatable (see Young, 1966) sucrose pellets.

\section{SUBJECTS}

Eight experimentally naive female albino rats from Rolfsmeyer Co., Madison, Wisconsin, were housed in individual cages in which Purina Lab Chow and water were continuously available. Two Ss were discarded early in runway training for failure to eat reward pellets.

\section{APPARATUS}

The start box (SB), first runway ( $R W$ ), and first goal box (GB) described by Dachowski (1967) were used. The SB, RW, and $G B$ were 10,16 , and 14 in. long, respectively, and were painted black. The SB and GB were $3 \mathrm{in}$. wide, and $\mathrm{RW}$ was $2 \frac{1}{2}$ in. wide. Photocells placed 2,14 , and 23 in. beyond the SB door measured start, running, and goal times, respectively. The $31 / 2-x 11-$ in. pretraining box was painted gray.

\section{PROCEDURE}

Seven days of exposure to reward pellets (P.J. Noyes Co., $37-m g$ sucrose) were given prior to runway training. On the first two days of this seven-day period, 100 pellets were presented to each $S$ in the home cages; on both the third and fourth days 10 pellets were given in the pretraining box and 50 pellets in the home cages; on the fifth day each $S$ received two placements in the pretraining box with five pelle ts present on each placement, and 50 pellets in the home cage; on the six th day 14 placements were given each $S$ with three pellets present; on the seventh day 15 placements with three pellets present were given, and latency to the start of eating was recorded for each placement.

The Ss were ranked on these eating latency scores from the seventh day of pretraining and these rankings were used to match $100 \%$ and $50 \%$ groups.

Runway trials were given in blocks of four. One block was given on each of the first two runway training days, and two blocks were given on each of the next nine days, for a total of 20 blocks. The intertrial interval was about $4 \mathrm{~min}$ and the time between blocks on the same day was approximately $1 \mathrm{~h}$. The $100 \%$ Ss received three pellets in GB on each trial, and $50 \% \mathrm{Ss}$ received three pellets on each rewarded trial. The $50 \%$ Ss received rewards $(R)$ and nonrewards $(N)$ in one of the following orders for each block: RRNN, RNRN, RNNR, NRRN, NRNR, and NNRR. These orders were randomly permuted for each six blocks for each $50 \%$ S for Blocks 2 through 19. Choice of orders for the first and last blocks were restricted so that the first and last trials were rewarded for all Ss. On each trial $S$ was placed in SB facing away from RW. When $\mathrm{S}$ oriented toward RW for about $1 \mathrm{sec}$, an opaque guillotine door was raised, and $1 \mathrm{sec}$ later a transparent door was raised giving $S$ access to $R W$ and starting the timing circuits.

\section{RESULTS AND DISCUSSION}

Reciprocal start, running, and goal times are plotted in Fig. 1 for the 10 days of training. Each speed measure was subjected to an analysis of variance in which groups $(50 \%$ and $100 \%$ ) was a between-Ss variable, and days, blocks-withindays, and trials-within-blocks were repeated-measure within-S variables. The first two blocks were considered the first day for purpose of analysis, although they were actually obtained on two successive days. The main effect of percentage reinforcement was not significant for any of the three response measures. Significant day effects for the start $(F=4.79)$, running $(F=9.17)$, and goal measures $(F=14.25$; all with $\mathrm{df}=9 / 36, p<.01$ ) reflect the overall learning increase from the first through the 10th day. The Day by Block interaction for start scores $(F=2.38, \mathrm{df}=9 / 36, \mathrm{p}<.05)$, and the Day by Block by Trial interaction for goal speed $(F=1.72$, $\mathrm{df}=27 / 108, \mathrm{p}<.05$ ), reflect simply the acquisition of the running response, and are the result of breaking the overall negatively-accelerated learning curves into sections and subsections that necessarily differ in slope between early and late training periods.

The significance of the apparent C.E seen in the running-speed and goal-speed ${ }^{2}$ curves is indicated by the Percentage by Day interactions (running speed: $F=\mathbf{2 . 2 3}$, $\mathrm{df}=9 / 36, \mathrm{p}<.05$; goal speed: $F=3.65, \mathrm{df}=9 / 36, \mathrm{p}<.01$ ). No other main effects or interactions were significant. ${ }^{3}$

The occurrence of the $\mathrm{CE}$ in running speeds is similar to data gathered with food-deprived Ss. However, the absence of 


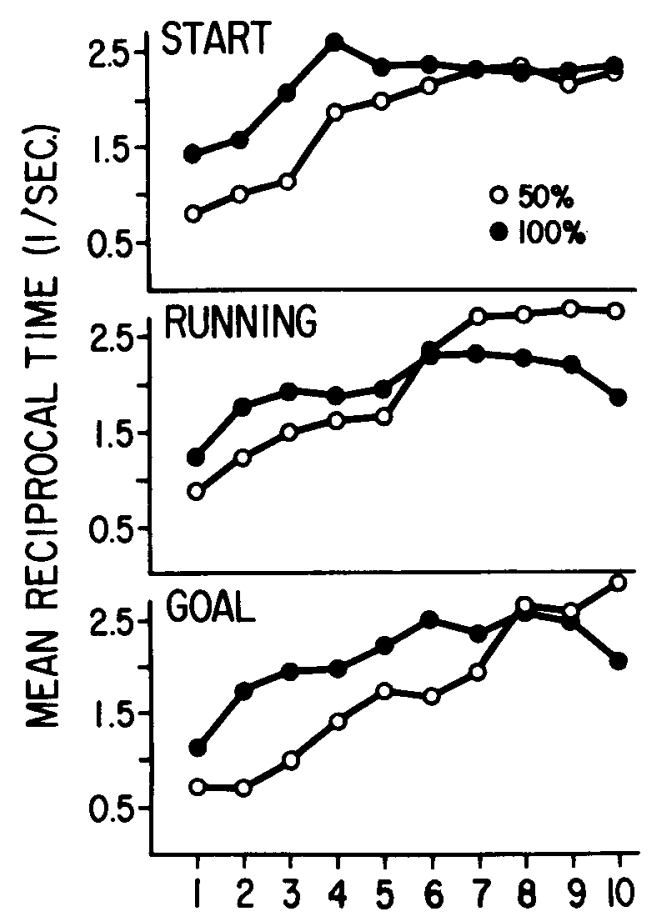

Fig. 1. Mean reciprocal start, running, and goal times for $50 \%$ and $100 \%$ Ss for the 10 days of acquisition (eight trials/day).

any apparent $C E$ for start scores is at variance with previous findings which indicate that, if the $\mathrm{CE}$ is obtained in an experiment for any response measure at all, it is invariably found in the measure taken earliest in the response chain (Amsel, Rashotte, \& MacKinnon, 1966; Goodrich, 1959; Haggard, 1959; Surridge, Boehnert, \& Amsel, 1966; Wagner, 1961, 1963; Weinstock, 1958). Perhaps low drive leads to less generalization of $r_{f}$ to earlier. portions of the runway. Although in most studies the CE is absent in the goal scores, Robbins \& Weinstock (1967) found, as in the present study, a CE for goal speed.

The finding of a significant $\mathrm{CE}$ under zero deprivation suggests that $r_{f}$ develops relatively independent of deprivation level. It seems that when incentive is sufficient to support learning, whether that incentive is compounded of deprivation-induced need and need satisfiers, "hedonic" factors, or other variables, such incentive may also be sufficient to support certain frustrative nonreward phenomena.

\section{REFERENCES}

AMSEL, A. The role of frustrative nonreward in noncontinuous reward situations. Psychological Bulletin, 1958, 55, 102-119.

AMSEL, A., RASHOTTE, M. E., \& MacKINNON, J. R. Partial reinforcement effects within subject and between subjects. Psychological Monograph, 1966, 80 (20, Whole No. 628).

BADIA, P. Effects of drive, reinforcement schedule, and change of schedule on performance. Journal of Experimental Psychology, 1965, 69, 292-297.

DACHOWSKI, L. Reward size effects in the double runway. Psychonomic Science, 1967, 9, 157-158.

GOODRICH, K. P. Performance in different segments of an instrumental response chain as a function of reinforcement schedule. Joumal of Experimental Psychology, 1959, 57, 57-63.

HAGGARD, D. F. Acquisition of a simple running response as a function of partial and continuous schedules of reinforcement. Psychological Record, 1959, 9, 11-18.

McHOSE, J. H., \& LUDVIGSON, H. W. Frustration effect as a function of drive. Psy chological Report, 1964, 14, 371-374.

NELSON, P. B., \& WOLLEN, K. A. Effects of ethanol and partial reinforcement upon runway acquisition. Psychonomic Science, 1965 , 3, 135-136.

ROBBINS, D., \& WEINSTOCK, S. The effects of nonreinforcement on subsequent running behavior under continuous reinforcement. Psychonomic Science, 1967, 9, 7-8.

SPENCE, K. W. Behavior theory and learning. Englewood Cliffs, N.J.: Prentice Hall, 1960.

SURRIDGE, C. H., BOEHNERT, J., \& AMSEL, A. Effect of interpolated extinction on the reacquisition of partially and continuously rewarded responses. Joumal of Experimental Psychology, 1966, 72, 564-570.

WAGNER, A. R. Effects of amount and percentage of reinforcement and number of acquisition trials on conditioning and extinction. Journal of Experimental Psychology, 1961, 62, 234-242.

WAGNER, A. R. Sodium amytal and partially reinforced runway performance. Journal of Experimental Psychology, 1963, 65, 474-477.

WEINSTOCK, S. Acquisition and extinction of a partially reinforced running response at a 24-hour intertrial interval. Journal of Experimental Psychology, 1958, 56, 151-158.

YOUNG, P. T. Hedonic organization and regulation of behavior. Psychological Review, 1966, 73, 59-86. NOTES

1. Supported by PHS Research Grant No. MH1 2099 from the National Institute of Mental Health. Computer processing of data was supported by the Computer Laboratory of Tulane University.

2. We are somewhat dubious about the magnitude of the CE in the goal-speed data, since it seems at least partly attributable to the inexplicable sharp downturn for Day 10 of the $100 \%$ group and the upward spurt of the $50 \%$ group on that day. More stable curves based on a larger number of $\mathrm{Ss}$, or additional training trials, might have clarified the matter.

3. Complete summary tables of the analyses of variance and tables of cell means may be obtained by writing to the first author.

\section{(Continued from page 112)}

$\mathrm{p}<.05)$. The difference at $16 \mathrm{~h}$ did not reach significance $(t=1.74, d f=8, p>.05)$ because of large variance in the Learned-Recipient group.

The results showed an apparent "transfer of learning" at $8 \mathrm{~h}$ after injection, suggesting that previous negative results may have been due to nonoptimal intervals between injection and test.

Further investigations are in progress to study the variables of injection dosage and locus, specificity of transfer, and task difficulty, in addition to postinjection delay.

\section{REFERENCES}

BABICH, F. R., JACOBSON, A. L., BUBASH, S., \& JACOBSON, A.

Transfer of a response to naive rats by injection of ribonucleic acid extracted from trained rats. Science, $1965,149,656-657$.

FJERDINGSTAD, E. J., NISSEN, T., \& ROIGAARD-PETERSEN, H. H. Effect of ribonucleic acid (RNA) extracted from the brain of trained animals on learning in rats. Scandinavian Journal of Psychology, 1965, $6,1-6$.

GAY, R., \& RAPHELSON, A. "Transfer of learning" by injection of brain RNA: A replication. Psychonomic Science, 1967, 8, 369-370.

LUTTGES, M., JOHNSON, T., BUCK, C., HOLLAND, J., \& McGAUGH, J. An examination of "transfer of learning" by nucleic acid. Science, $1966,151,834-837$.

\section{NOTES}

1. One Donor-Learned rat was discarded after failing to learn the passive avoidance.

2. Joseph Quashnock carried out the extraction procedure. 